\title{
On the application of Electro-sinter-forging to the sintering of high-karatage gold powders
}

\author{
I. Forno ${ }^{1} \cdot$ M. Actis Grande ${ }^{1} \cdot$ A. Fais ${ }^{2}$
}

Published online: 18 November 2015

(C) The Author(s) 2015. This article is published with open access at SpringerLink.com

\begin{abstract}
Precious metals are widely used for a variety of applications, among which are luxury goods, biomedical devices, and electronic components. Requiring precise components, those sectors are usually looking into lost-wax casting, machining, and, more recently, metal injection moulding. Material or (thermal) energy consumption and demand for the aforementioned processes are mainly suitable for stable crystalline structures. The applicability of a field-assisted sintering technique (FAST)-Electro-Sinter-Forging (ESF) - to a high-karatage gold powder is explored in the present research work. FAST is characterized by extremely rapid processing times, also enabling the production of metastable phases. Different powders with different features (as atomized, ball-milled, and admixed with nanodiamonds) were taken into account and fast-sintered; and the resulting samples were analyzed in terms of final density, microstructure, and hardness.
\end{abstract}

Keywords Gold alloys · Powder metallurgy ·

Electro-sinter-forging $\cdot$ Hardness

\section{Introduction}

In the last decades, the high-quality jewelry industry, traditionally based on handcraft abilities, has been facing a rising

I. Forno

ilaria.forno@polito.it

1 Department of Applied Science and Technology, Alessandria Campus, Politecnico di Torino, Viale Michel 5, 15121 Alessandria, Italy

2 EPoS Srl, Strada delle Cacce 73, 10139 Torino, Italy interest towards new technologies and innovative materials. This renovation, mainly driven by the specific global scenario, is concerning several aspects of the industrial field, such as the introduction of new technologies [1-3] and materials [4, 5], the exploitation of new design features [6], and the opening towards new markets. When considering product innovation, two different aspects have to be taken into account: material optimization and process enhancement.

On one hand, new materials have been introduced (such as titanium alloys, stainless steel, and ceramics, traditionally not applied in the jewelry industry) and, on the other hand, traditional materials were optimized, enhancing their properties both via compositional optimization and via processing conditions tuning. In this fragmented and sparkling scenario, a great interest rose towards innovative production processes. The intensive work to demonstrate the applicability of rapid prototyping, machining, and powder metallurgy to precious metals is clearly showing this trend [7-10]. Coming to the specific case of powder metallurgy $(\mathrm{P} / \mathrm{M})$, the application of this technique has been driven both by metallurgical (great opportunities in terms of properties and compositions) and production (dimensional tolerances, shape complexity, etc.) considerations. $\mathrm{P} / \mathrm{M}$ is well-exploited in many industrial fields, producing components starting from metal in the powder shape and form then consolidated without passing through the (complete) melting of the powder particles. The free space which is present in between powder particles once compacted is gradually reduced during the sintering process, as a consequence of the reduction of Gibb's free energy [11, 12]. A perfect balance of sintering variables and powder particle features is enabling the optimization of the sintered structure: low residual porosity and fine grain size. Additional properties may be achieved by the ball milling of metal powders [13]. Ball milling is a well-exploited method to get comminution, mechanical alloying, and structural modification of metallic 
and non-metallic powder. In particular, high energy ball milling (HEBM) is an advantageous technique to produce nanocrystalline materials, producing bulk quantities of materials in the solid state in relatively simple to achieve conditions (room temperature and simple equipment). The milling process is causing a progressive reduction of grain size, up to the formation of dislocation-free nanocrystalline grains. The consolidation of mechanical milled powders is the key point in order to produce bulk components $[14,15]$. In this frame, the use of advanced sintering processes is even amplifying the opportunities offered by $\mathrm{P} / \mathrm{M}$, both in terms of final component properties and of manufacturing conditions.

In the last years, particular interest has been devoted to field-assisted sintering techniques (FAST) and electric current assisted sintering techniques (ECAS) $[16,17]$ due to their ability to reach high densities in very short processing times. Capacitor discharge sintering (CDS) is a specific electrodischarge sintering technique, directly derived from capacitor discharge welding.

In CDS, two inductively coupled circuits and a step down transformer are used to decrease the voltage previously loaded on the capacitor bank (in the primary) and increase the current on the powder compact (in the secondary). The loose powder to be sintered is loaded into a conductive mold then compacted by means of an oleo-dynamic press (Fig. 1). Once the compaction pressure is reached, the two circuits are coupled and an electric current flows directly through the powder, sintering the component [18].

The sintering sequence is divided into different stages: (a) slow pre-compaction to a target clearance, (b) high-speed movement with simultaneous single electro-magnetic pulse, (c) hold of the clearance value, (d) pressure release, and (e) expulsion of the sintered piece.

The electro-magnetic pulse is sintering the powder in a lapse of time lasting typically between 30 and $100 \mathrm{~ms}$.

Among the different FAST, CDS and its particular case Electro-Sinter-Forging (ESF), resulted to be particularly interesting in terms of the required automation and sintering time [milliseconds in ESF compared to minutes of spark plasma

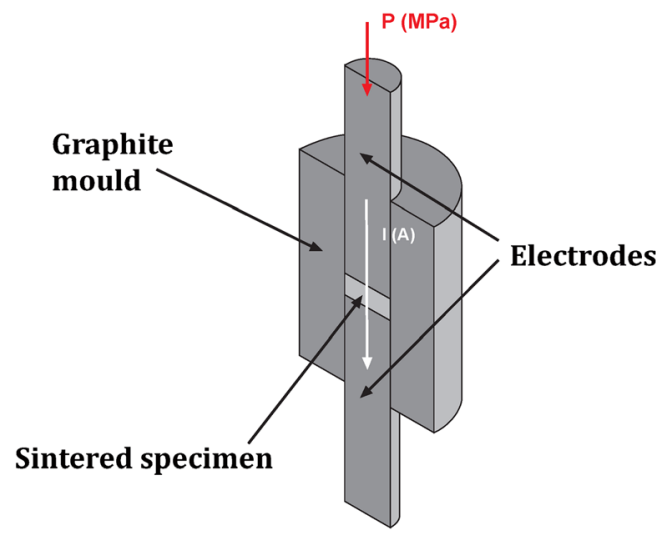

Fig. 1 CDS apparatus schematic outline sintering (SPS)]. Despite the extremely quick process, timing is not the main benefit derived from ESF: the actual possibility of retained nanosized or amorphous structures and metastable compounds is highly widening the range of producible materials [19].

Effective sintering of metal matrices containing diamonds is a challenging topic of high interest, particularly in the production of abraders and cutting tools [20, 21]. Sintering of these composites is usually carried out recurring to the creation of a protective interface between the metal matrix and diamonds, in order to prevent the risk of diffusive phenomena of carbon into the metal matrix which may seriously erode the diamonds and produce weak components [22-25]. FAST techniques, being characterized by extremely rapid processing and by a pulse-generated heating method without significant thermal energy losses, are fundamentally different from conventional thermal sintering thus enabling the production of a metastable structure [26]. By carefully choosing the diamond size and metal matrix, the same process may be applied to obtain a high-end luxury good combining the preciosity of both the matrix and reinforcement to get an enhanced and innovative jewelry material.

The present work is devoted to the study of the applicability of electro-sinter forging (ESF) to a set of high-karatage gold powders, processed in different conditions.

Produced samples were tested in order to evaluate the main properties and check the fulfillment of jewelry industry requirements. Densities and microstructures have been evaluated in order to estimate the accomplishment of polishing requirements.

As pointed out in several different studies [27-29], hardness is often used in the jewelry industry since it can be easily and quickly measured. Generally speaking, the harder the metal, the easier to polish it and the more wear- and scratchresistant it will be. Many efforts have therefore been devoted to increase the hardness of precious metals, particularly of gold alloys, both from a compositional point of view [30, $31]$ and via process optimization [32].

Hardness of the different systems studied have been measured in terms of the Vickers scale.

\section{Materials and methods}

\section{Powders}

In this experimental work, different high-karatage gold powders have been evaluated. Table 1 reports the alloy compositions and the main powder characteristics of the systems taken into account for the research.

Metal powders have been produced via gas atomizing, resulting in a highly packable spherical shaped powder. System A is a pre-alloyed high-karatage gold 
Table 1 Composition of the studied systems

\begin{tabular}{llllll}
\hline Alloy & $\mathrm{Au}$ & $\mathrm{Co}$ & $\mathrm{Cu}$ & $\mathrm{Ag}$ & Powder modification \\
\hline $\mathrm{A}$ & 99.8 & 0.2 & & & $/$ \\
$\mathrm{B}$ & 75 & & 12.5 & 12.5 & $/$ \\
$\mathrm{C}$ & 75 & & 12.5 & 12.5 & Ball-milled \\
$\mathrm{D}$ & 75 & & 12.5 & 12.5 & $+15 \%$ vol. nanodiamonds \\
\hline
\end{tabular}

alloy powder; alloying with $0.2 \% \mathrm{Co}$ was finalized to grain refining. System B, C, and D use the same starting alloy based on a standard $18 \mathrm{kt}$. $3 \mathrm{~N}$ gold composition. Figure 2 reports the $18 \mathrm{kt}$. $3 \mathrm{~N}$ gold powder used in systems B, C and D

System $\mathrm{C}$ has been obtained carrying out a ball-milling process onto system B. Powder B was ground in a highenergy planetary mill apparatus Retsch PM-100 with a 50$\mathrm{ml}$ WC jar and WC balls. Milling was carried out with a ball-to-powder weight ratio of 10:1 and a $3 \mathrm{ml}$ addition of ethanol as wetting agent at $300 \mathrm{rpm}$. Powder D was obtained by means of mixing system B with $15 \%$ vol. of nanodiamonds (sub $250 \mu \mathrm{m}$.).

\section{Processing}

Powders have then been pressed and sintered with an ESF process. Samples have been sintered in a high-strength graphite mould with a central circular sintering cavity with a diameter of $10 \mathrm{~mm}$. The plungers also act as electrodes and are made of copper alloys (typically $\mathrm{Cu}-1.5 \% \mathrm{Co}-0.5 \% \mathrm{Be}$ ). Different sintering trials were carried out with different applied pressures (40 to $210 \mathrm{MPa}$ ) with a final clearance of $4.6 \mathrm{~mm}$.

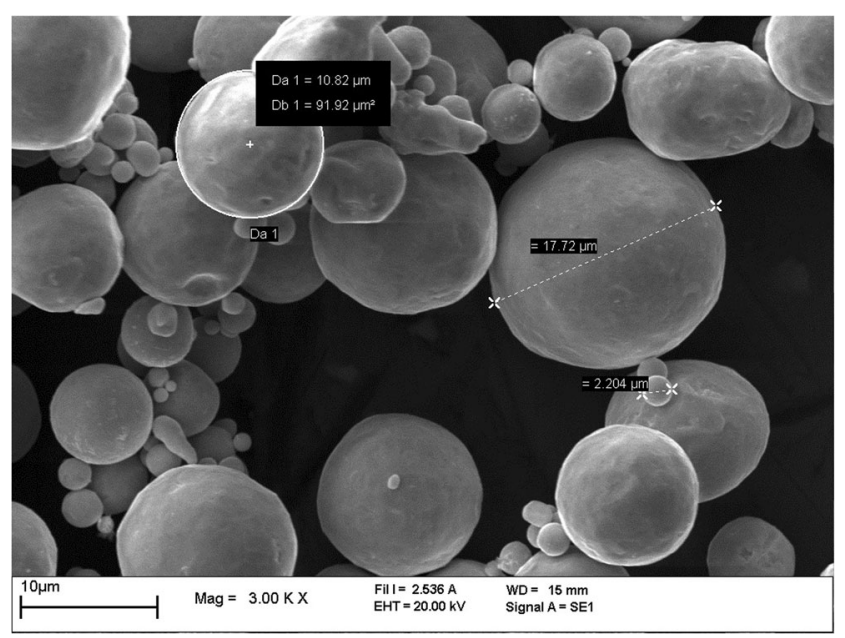

Fig. 218 kt. $3 \mathrm{~N}$ yellow gold alloys powder particles

\section{Testing}

Density was tested with Archimedes' principle on assintered samples, by means of an equipped five-digitSartorius CPA225D balance in controlled conditions. Metallographic inspection has been carried out via light optical microscopy both on polished and etched samples. Chemical micro-etching has been carried out with a $\mathrm{HCl} / \mathrm{HNO}_{3}$ etchant according to the ASTM standard E407-99. Moreover, scanning electron microscopy (SEM) morphological analysis has been carried out on polished sample in order to further deepen the understanding of sintering conditions. Mechanical properties of sintered samples have also been evaluated mainly in terms of microhardness (HV of 0.1-15), via a LEICA VMHT hardness test.

\section{Results and discussion}

\section{Microscopy}

\section{4 kt. Gold}

The AuCo alloy (99.8\% $\mathrm{Au}-0.2 \% \mathrm{Co})$ showed a relative sintered density of $98.7 \%$. The microstructure of sintered AuCo 24kt. gold alloy is reported in Figs. 3 and 4.

The sintered etched microstructure revealed a spherical porosity that was evenly distributed along the grain boundaries, with a mean dimension lower than $5 \mu \mathrm{m}$. Cobalt aggregates are homogenously distributed at grain boundaries, maintaining a grain dimension of lower than $30 \mu \mathrm{m}$.

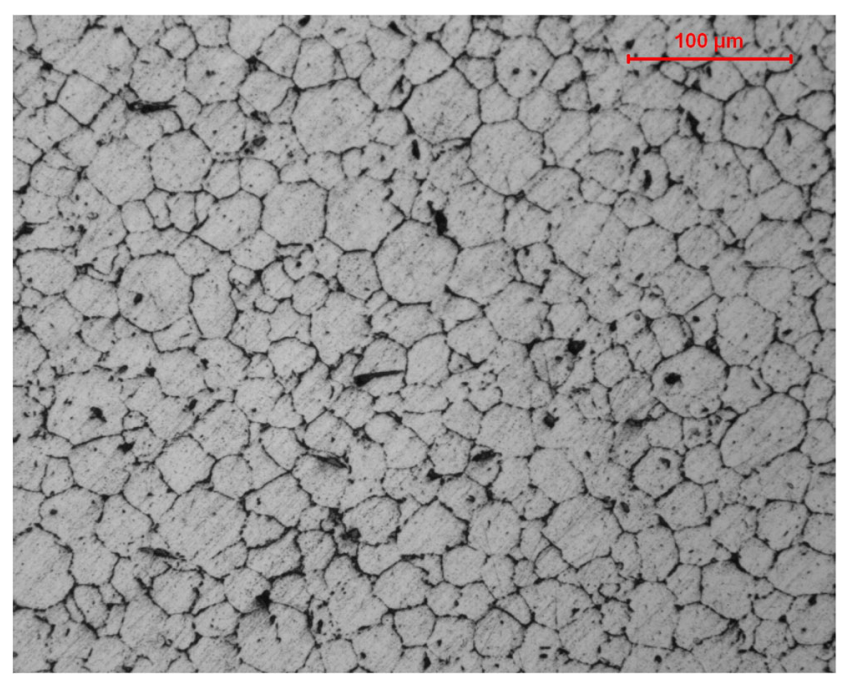

Fig. 3 Light optical microscopy (LOM) analysis of 24 kt. microalloyed gold $(200 \times)$ 


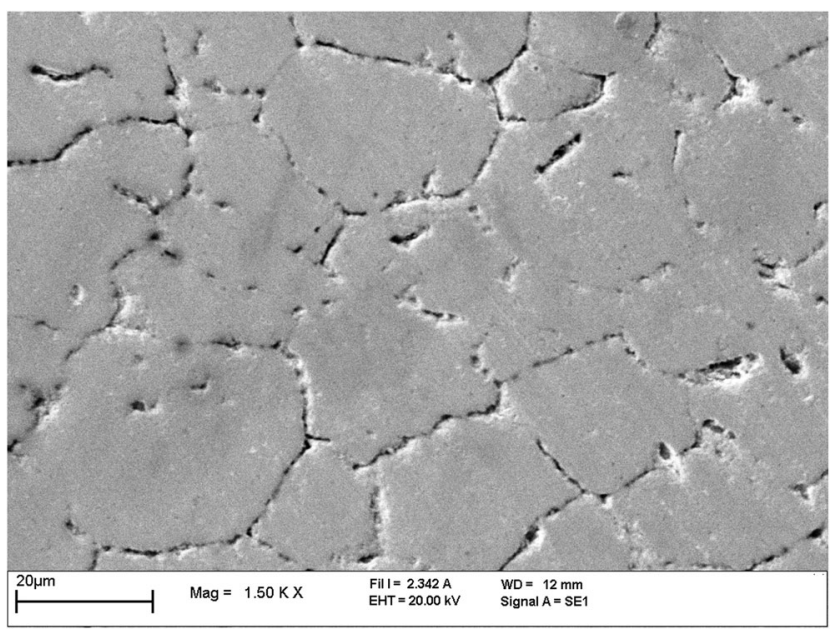

Fig. 4 SEM analysis of 24 kt. microalloyed gold

Figure 4 shows the SEM image of the system A, highlighting the distribution of $\mathrm{Co}$ along grain boundaries.

\section{$18 \mathrm{kt} .3 \mathrm{~N}$ yellow gold alloy}

The metallurgical analysis of system B shows easily detectable powder particles, with evidence of inner dendritic structures (Fig. 5). SEM analysis reported in Fig. 6, reveals the presence of a copper-rich phase distributed along grain boundaries, presumably originated by the instantaneous formation of a liquid phase (Ag-Cu eutectic) during the electrical pulse.

In the observed structure, sintering of particles, at least at its early stages, is clearly noticeable; given the short sintering time and, most of all, the overall low $\mathrm{T}$ of the process, no diffusion effects may occur. System B showed a relative sintered density of $98.5 \%$.

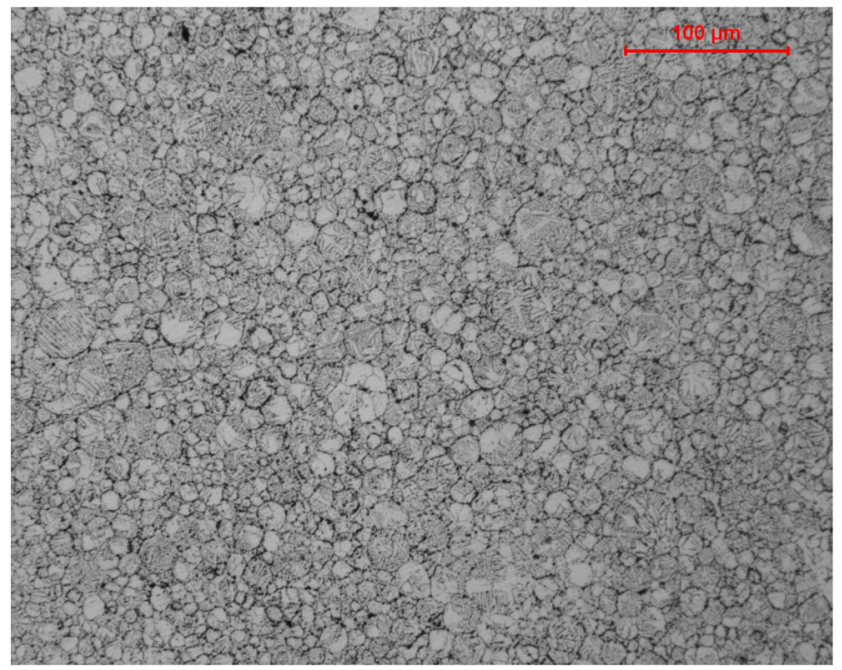

Fig. 5 LOM analysis of 18 kt. 3N gold alloy (200×)

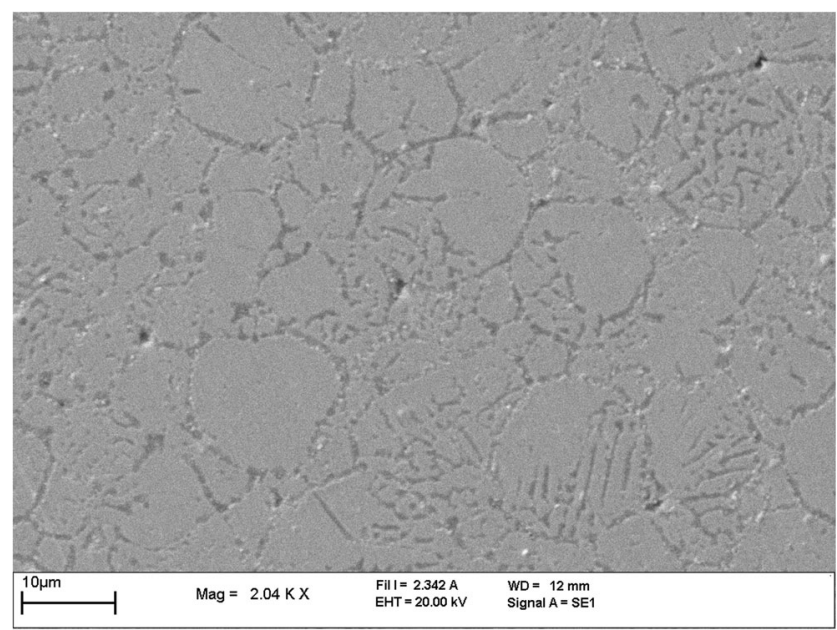

Fig. 6 SEM analysis of 18 kt. $3 \mathrm{~N}$ gold

\section{$18 \mathrm{kt}$. $3 N$ yellow gold alloy-ball-milled}

A 128-h ball milling resulted in a nanostructured powder partially amorphous. The sintering of this powder resulted to be extremely advanced. No microstructure or grain boundaries are therefore detectable by SEM analysis in Fig. 7, while at high magnification (Fig. 8), it is possible to identify submicron precipitates in nanocrystalline gold.

A relative sintered density of $98.9 \%$ was obtained on system C.

\section{8 kt. 3N yellow gold alloy with nanodiamonds}

Sintering of system D resulted in the successful creation of a composite material. Reinforcing agents (nanodiamonds) are effectively dispersed in the metal matrix. The homogeneity of the dispersion of the second phase is dependent on the mixing process prior the sintering and on the relative powder dimension.

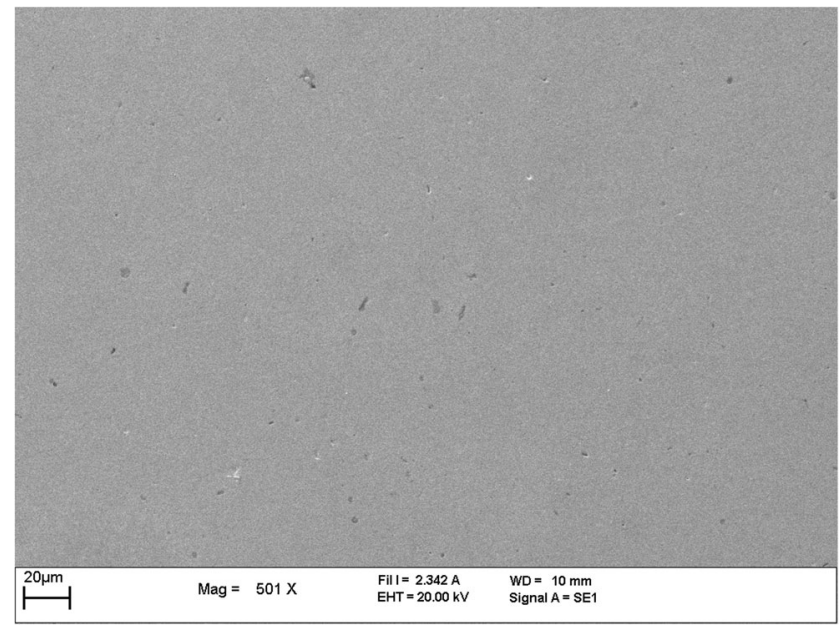

Fig. 7 SEM analysis of ball-milled 18 kt. $3 \mathrm{~N}$ gold 


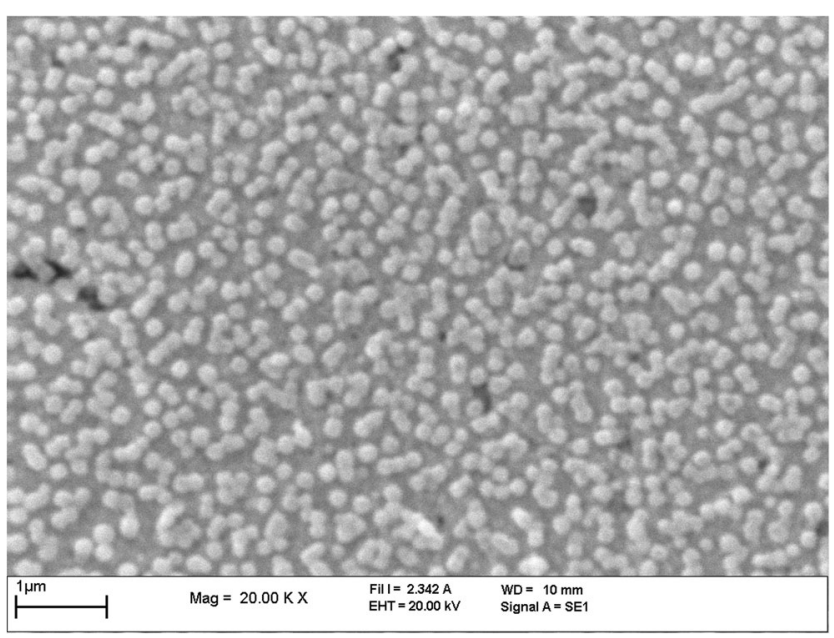

Fig. 8 SEM analysis of ball-milled 18 kt. $3 \mathrm{~N}$ gold

Figures 9 and 10 show the homogeneous dispersion of nanodiamonds into the matrix at a local level. Diamond powder is clearly visible and detectable testifying the absence of deteriorating phenomena at the interface.

\section{Microhardness}

Microhardness results have been compared with average values for the corresponding composition (Fig. 11). $24 \mathrm{kt}$. gold has Vickers hardness of about 20-30 HV in the as-cast or soft-annealed form, reaching $60 \mathrm{HV}$ for microalloyed gold [31]. The application of ESF is improving this result up to $80 \mathrm{HV}$, mainly thanks to the effective dispersion of the alloying element and to the grain fineness.

A much more significant effect is observed in the considered 18kt. alloys. $3 \mathrm{~N}$ gold has a hardness of $150 \mathrm{HV}$ in the soft-annealed state $[33,34]$. The application of ESF allowed to reach a hardness of $180 \mathrm{HV}$ for the simple 18kt. (system B). Considering system $\mathrm{D}$, the addition of a hard second phase

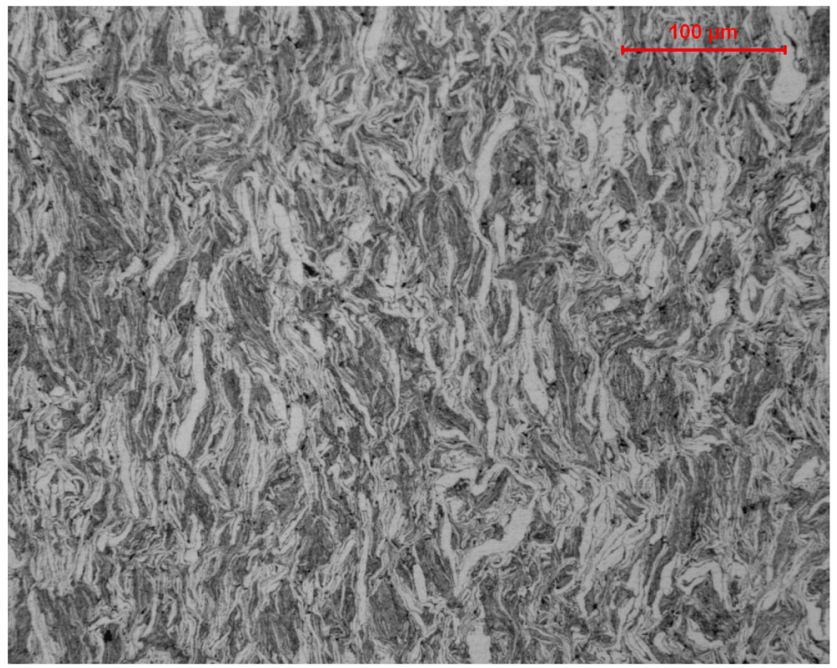

Fig. 9 LOM analysis of 18 kt. $3 \mathrm{~N}$ gold + nanodiamonds (200×)

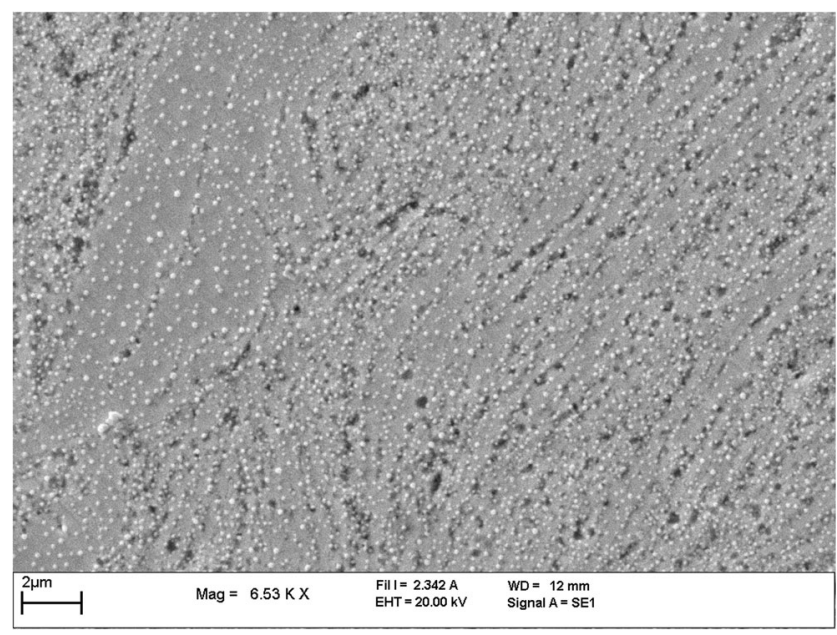

Fig. 10 SEM analysis of 18 kt. $3 \mathrm{~N}$ gold + nanodiamonds

increased the hardness value to $220 \mathrm{HV}$. The possibility to introduce and, most of all, retain a nanostructured systems allowed to reach $280 \mathrm{HV}$ on system C.

\section{Conclusions}

The applicability of a new processing technique to gold powders has been demonstrated. The use of this approach allows reaching, in a single-step process, increased hardness values compared to traditional casting techniques. The application of ESF also enables the production of metastable structures in a reliable and controlled way, thus widening the possibilities in terms of precious (and non precious) alloys with enhanced properties.

When coming to the implementation of this approach in precious metals industry, some additional conclusions may be drawn on suitable shapes and size.

- Considering the dynamics of the compaction, this technique is equivalent to uniaxial pressing. Thus, suitable geometries may be limited due to the difficulties in the lateral flow of the powder into the die and in part ejection. Suitable parts have vertical or near-vertical sides, eventually with different steps and/or vertical undercuts and holes (rounded or not). Virtually applicable to any size, tooling and press capabilities impose size and shape constraints on parts that can be fabricated.

- Compaction and sintering are carried out in the same production step; hence, the surface quality of the sintered part is therefore highly influenced by the surface finish of the die cavities and punches. Mirror-polished punches result in a highly smooth surface; therefore, the sintered part requires little finishing.

- The final polishing of the object, being almost fully dense and with a homogenous microstructure, is not hindered by 
Fig. 11 Hardness value of sintered samples

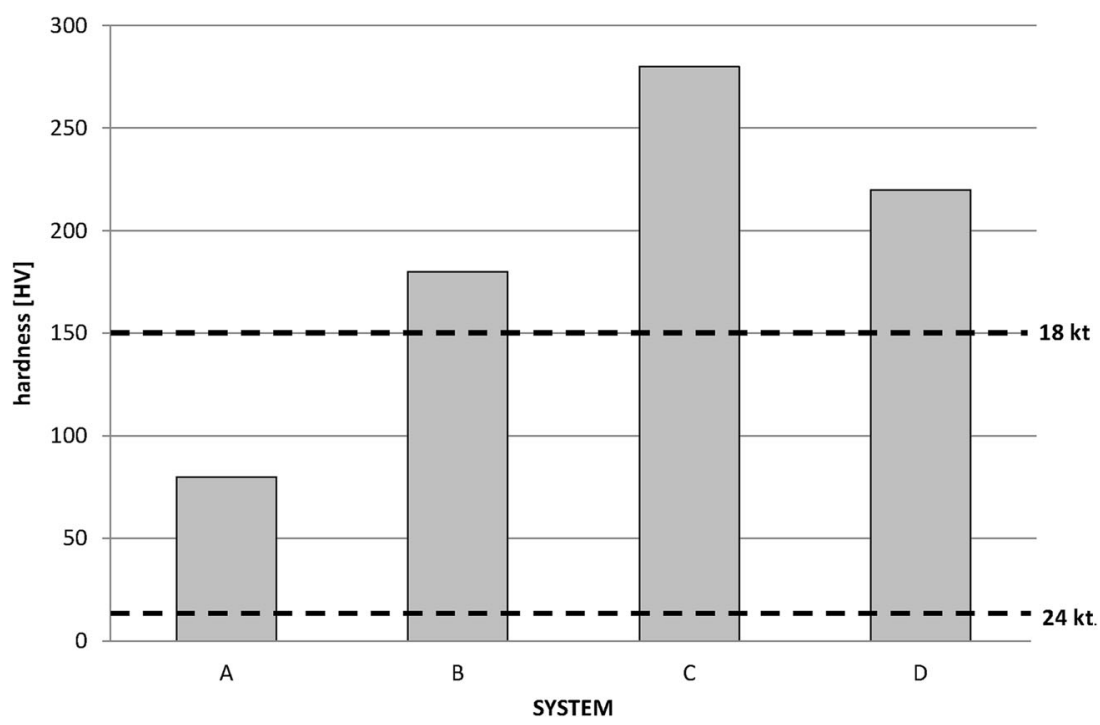

porosity or hard spots. Nevertheless, the increased hardness may be considered as a limitation, and the use of appropriate polishing media and tools has to be taken into account.

- Since any thermal cycle during post-processing (such as annealing, soldering and others thermal treatments) may modify the grain size, ESF may be interesting when applied to near-net-shape objects or components.

Acknowledgments The authors would like to thank Mr. Walter Niedermann for his support and interest in the research work and Dr. Christopher Corti for the precious advice.

Open Access This article is distributed under the terms of the Creative Commons Attribution 4.0 International License (http:// creativecommons.org/licenses/by/4.0/), which permits unrestricted use, distribution, and reproduction in any medium, provided you give appropriate credit to the original author(s) and the source, provide a link to the Creative Commons license, and indicate if changes were made.

\section{References}

1. Henriques B, Pinto P, Souza J, Teixeira JC, Soares D, Silva FS (2013) On the hot pressing of coloured high-gold alloys powder compacts applied to the manufacturing of innovative jewellery items. Gold Bull 46(2):117-125

2. Forno I (2014) Direct casting of rapid prototyping resins for luxury production: influence of burn-out and processing parameters on the final quality. Int J Eng Sci Innov Technol 3(2):498-507

3. Cooper F (2012) "Sintering and additive manufacturing: the new paradigm for the jewelry manufacturer," Proc Santa Fe Symp Jewel Manufac Technol 103-122

4. Schroers J, Lohwongwatana B, Johnson WL, Peker A (2007) Precious bulk metallic glasses for jewelry applications. Mater Sci Eng A 449-451:235-238

5. Forno I, Priarone PC, Settineri L, Actis Grande M (2014) Surface characterization and machinability of zirconium alloys in view of jewelry application. Adv Mater Res 941-944:18-25
6. Bohez EJ, Wannarumon Kielarova S, and Pradujphongphet $\mathrm{P}$ (2015) "new interactive-generative design system: hybrid of shape grammar and evolutionary design - an application of jewelry design," in Advances in Swarm and Computational Intelligence SE 33, vol. 9140, Y, Eds. Springer International Publishing 302-313

7. Raw PM (2000) Development of a powder metallurgical technique for the mass production of carat gold wedding rings. Gold Bull 33(3):79-88

8. Khan M, Dickens P (2010) Selective laser melting (SLM) of pure gold. Gold Bull 43(2):114-121

9. Fischer-buehner J, Poliero P, Bertoncello R, Basso A (2011) "Rapid jewelry manufacturing by laser melting of Precious Metal Powders (PLM): FICTION OR Future?," Proc St Fe Symp Jewel Manuf Technol 177-202

10. Grande MA, Forno I (2014) Innovation and optimization of the investment casting of precious alloys. Acta Metall Slovaca 20: 341-352

11. German RM (2005) Powder metallurgy and particulate materials processing: the processes, materials, products, properties, and applications. Metal Powder Industries Federation, Princeton

12. Upadhyaya GS, Upadhyaya A (2011) Powder metallurgy: science, technology, and materials. Universities press, Boca Raton

13. Suryanarayana C (2001) Mechanical alloying and milling. Prog Mater Sci 46(1-2):1-184

14. Wang C, Ji W, Fu Z (2014) Mechanical alloying and spark plasma sintering of CoCrFeNiMnAl high-entropy alloy. Adv Powder Technol 25(4):1334-1338

15. Li X, Cheng Z, Hu K, Chen H, Yang C (2015) Crystallization kinetics and spark plasma sintering of amorphous Ni53Nb20Ti10Zr8Co6Ta3 powders prepared by mechanical alloying. Vacuum 114:93-100

16. Groza JR, Zavaliangos A (2000) Sintering activation by external electrical field. Mater Sci Eng A 287(2):171-177

17. Orrù R, Licheri R, Locci AM, Cincotti A, Cao G (2009) Consolidation/synthesis of materials by electric current activated/ assisted sintering. Mater Sci Eng R Rep 63(4-6):127-287

18. Fais A (2010) Processing characteristics and parameters in capacitor discharge sintering. J Mater Process Technol 210(15):22232230

19. Fais A, Leoni M, Scardi P (2012) Fast sintering of nanocrystalline copper. Metall Mater Trans A Phys Metall Mater Sci 43(5):15171521 
20. Tillmann W (2000) Trends and market perspectives for diamond tools in the construction industry. Int J Refract Met Hard Mater 18(6):301-306

21. Kunimine T, Shibuya M, Sato H, Watanabe Y (2015) Fabrication of copper/diamond functionally graded materials for grinding wheels by centrifugal sintered-casting. J Mater Process Technol 217:294301

22. Klotz UE, Liu C, Khalid FA, Elsener H-R (2008) Influence of brazing parameters and alloy composition on interface morphology of brazed diamond. Mater Sci Eng A 495(1-2):265-270

23. Dhokey NB, Utpat K, Gosavi A, Dhoka P (2013) Hot-press sintering temperature response of diamond cutting tools and its correlation with wear mechanism. Int J Refract Met Hard Mater 36:289-293

24. de Oliveira LJ, Cabral SC, Filgueira M (2012) Study hot pressed Fe-diamond composites graphitization. Int J Refract Met Hard Mater 35:228-234

25. de Oliveira LJ, Bobrovnitchii GS, Filgueira M (2007) Processing and characterization of impregnated diamond cutting tools using a ferrous metal matrix. Int J Refract Met Hard Mater 25(4):328-335
26. Egan D, Melody S (2009) EDS as a method of manufacturing diamond tools. Met Powder Rep 64(6):10-36

27. Corti CW (2008) The role of hardness in jewellery alloys. In: Bell E (ed) Proceedings of the Santa Fe Symposium. Met-Chem Research Inc, Albuquerque, pp 103-120

28. Süss R, Lingen E, Glaner L, Toit M (2004) 18 carat yellow gold alloys with increased hardness. Gold Bull 37(3-4):196-207

29. Bernardin JE (2011) "Understanding microalloys," Proc Santa Fe Symp Jewel Manufac Technol 53-64

30. Toit M, Lingen E, Glaner L, Süss R (2002) The development of a novel gold alloy with 995 fineness and increased hardness. Gold Bull 35(2):46-52

31. Corti CW (1999) Metallurgy of microalloyed 24 carat golds. Gold Bull 32(2):39-47

32. Tian B, Yang Z, Pan X, Meng Y (2011) Effect of thermal treatment on the hardness of low gold content dental casting Ag-Pd alloy. Rare Met Mater Eng 40(5):773-777

33. Grimwade M (2009) Introduction to precious metals, Ed. McCreight-Johnson, Brynmorgen Press pub

34. Porter DL (2004) Smithells metals reference book. Elsevier 